\title{
Nueva ética para nuevos tiempos: la moral en la industria 4.0*
}

\author{
doi: 10.52749/fh.v2i1.1
}

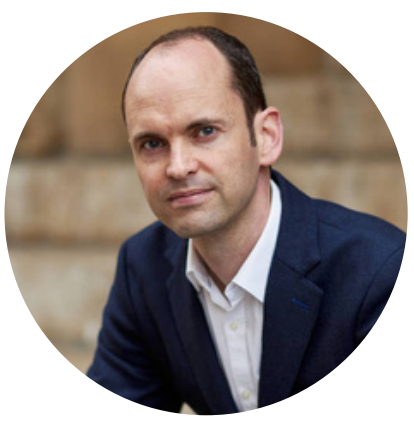

\section{TOBY ORD}

Toby Ord es investigador senior en filosofía en la Universidad de Oxford. Su trabajo se centra en las cuestiones generales que enfrenta la humanidad. Su investigación actual se centra en el futuro a largo plazo de la humanidad y los riesgos que amenazan con destruir todo nuestro potencial. Ha asesorado a la Organización Mundial de la Salud, el Foro Económico Mundial y la Oficina del Primer Ministro del Reino Unido y la Oficina del Gabinete.

La pandemia de COVID-19 subraya cuán estrechamente entrelazada se ha vuelto la humanidad. Un solo animal infectado en algún lugar de China puso en marcha una reacción en cadena con efectos que, casi un año después, aún resuenan en todos los rincones del planeta.

Esto no debería ser particularmente sorprendente. La historia de las pandemias rastrea nuestra unificación como especie. La peste negra viajó por nuevas rutas comerciales forjadas entre Europa y Asia en la Edad Media. La viruela cruzó el Océano Atlántico con los europeos, devastando América. Y la pandemia de influenza de 1918 llegó a seis continentes en solo meses, debido a los avances tecnológicos en el transporte de mercancías y personas. Cada vez que la humanidad da pasos audaces hacia una integración más profunda, la enfermedad sigue.

Esto ha generado grandes beneficios. Ponemos en común nuestro conocimiento, innovación y tecnología. Compartimos las ricas tradiciones de las culturas de los demás. Cooperamos a través de grandes distancias, trabajando juntos en proyectos demasiado grandes para que cualquier individuo o país los complete por su cuenta, como la erradicación de la viruela de la faz de la Tierra.

Pero nuestra interconexión también conlleva profundos costos. Compartimos no solo nuestro mayor conocimiento y cultura, sino también nuestros mayores riesgos. Podemos pasar décadas sin verlo, pero nuestras actividades tienen un costo sombra en riesgo que eventualmente se vence. Y no se limita a las pandemias. Nuestra nueva capacidad para compartir información en todo el mundo permite que las ideas peligrosas (desinformación, ideologías deformadas y odio) se propaguen más rápido que cualquier enfermedad.

Estos desafíos de un mundo interconectado requieren nuevos enfoques de la ética, nuevas formas de comprender nuestra difícil situación y coordinar nuestra respuesta. La ética normalmente se ve desde la perspectiva del individuo: ¿qué debo hacer? Pero a veces damos un paso atrás para adoptar una perspectiva más amplia y pensar en términos de las obligaciones asumidas por las sociedades o los países. Y en los últimos siglos, hemos comenzado a adoptar una perspectiva global, preguntándonos cómo debería responder el mundo a una preocupación apremiante.

Estas nuevas perspectivas son demandadas por un mundo cambiante. Antes de que tuviéramos la civilización, rara vez habría tenido sentido pensar en responsabilidades más allá de nuestros vínculos inmediatos. Solo cuando nos unimos más y comenzamos a encontrar problemas verdaderamente globales, comenzamos a considerar nuestras obligaciones colectivas con nuestro planeta y con nosotros mismos.

Pero ahora tenemos que dar un paso más. Junto con nuestras interconexiones cada vez más enraizadas, también ha habido un cambio profundo en el alcance de nuestras acciones. Con el advenimiento de las armas nucleares, el poder creciente de la humanidad sobre el mundo que nos rodea finalmente llegó a un punto en el que podríamos destruirnos a nosotros mismos. Entramos en un mundo en el que podríamos amenazar no solo a todos los que viven hoy en día, sino a todos los que pudieran continuar y todo lo que pudieran lograr; donde podríamos traicionar no solo la confianza de todos los que viven hoy, sino de las diez mil generaciones que nos precedieron.

A medida de que nuestro poder continúa creciendo, también lo hacen los riesgos: desde el cambio climático extremo hasta las biotecnologías venideras que permitirán pandemias diseñadas con 
una letalidad y transmisibilidad más allá de lo que la naturaleza ha producido. Tales amenazas a todo nuestro futuro, ya sea a través de nuestra extinción o un colapso irrevocable de la civilización, se conocen como riesgos existenciales. La forma en que los abordemos determinará el destino de nuestra especie.

Hacer frente a este desafío requerirá una reorientación radical en nuestro pensamiento, viendo a nuestra generación como una pequeña parte de un todo mucho mayor; una historia que se extiende por eones. Por lo tanto, tendremos que adoptar no solo una perspectiva global, de todos los que viven hoy, sino la perspectiva de la humanidad misma: los cien mil millones de personas que nos precedieron, los casi ocho mil millones que viven hoy y las innumerables generaciones por nacer. Al adoptar este lente ético, tendremos una mejor visión de nuestro papel crucial en la historia más amplia de nuestra especie.

Pensar en estos términos a veces puede parecer antinatural, porque la humanidad no es un agente coherente. Tenemos profundos desacuerdos sobre lo que debemos hacer y estamos constantemente compitiendo entre nosotros. Luchamos por actuar en concierto incluso cuando es obvio que debemos hacerlo. Pero esto es cierto para todos los agentes colectivos y no nos impide referirnos a los intereses de una empresa o las prioridades de un país. No se trata de negar las diferencias y fuentes de fricción entre agentes humanos; se trata de preguntar qué podríamos lograr si actuamos juntos, o qué responsabilidades asumimos colectivamente.

Considere a toda la humanidad en términos de una sola vida humana. La especie típica sobrevive alrededor de un millón de años, y la humanidad tiene solo 200.000 años, lo que nos coloca en nuestra adolescencia. Esta parece una comparación especialmente adecuada, ya que, al igual que el adolescente, estamos viendo un rápido desarrollo en nuestra fuerza y en nuestra capacidad para meternos en problemas. Estamos casi listos para el mundo, listos para explorar el vertiginoso potencial que depara el futuro. Sin embargo, cuando se trata de riesgos, podemos ser impulsivos y descuidados, aprovechando los beneficios a corto plazo pero descuidando los costos a largo plazo.

Dentro de las sociedades individuales, resolvemos estas tensiones dando a los jóvenes suficiente espacio para crecer y prosperar, mientras que al mismo tiempo los alejamos de peligros que aún no comprenden. Solo gradualmente les otorgamos las libertades de la edad adulta, con la esperanza de haberles dado suficiente tiempo y orientación para tomar decisiones sabias y prudentes, y reconocer que con la libertad viene la responsabilidad. Desafortunadamente, la humanidad no tiene el lujo de contar con un guardián cariñoso. Estamos solos y tendremos que crecer rápido.

En última instancia, depende de nosotros que la humanidad sobreviva a este período crítico. Debido a que los mayores riesgos no provienen de la naturaleza, sino de nuestra propia acción, podemos alejarnos del abismo si lo deseamos. Podemos adoptar una actitud más madura ante nuestra creciente interconexión y progreso tecnológico, dejando de lado una fracción de los beneficios que aportan para protegernos de los riesgos asociados. De vez en cuando dar un paso atrás para adoptar la perspectiva de la humanidad nos permitirá ver nuestro predicamento con mayor claridad, proporcionando la visión que necesitamos para guiarnos.

* La Sociedad Secular Humanista del Perú tiene el permiso expreso del autor para traducir y republicar el artículo publicado originalmente el 04 de noviembre del 2020 en el portal del World Economic Forum con el título de "Why it's time for a new ethical perspective on humanity, according to a philosopher". Recuperado de: https://www.weforum.org/agenda/2020/11/globaliation-technology-toby-ord-professor-ethics-philosophy/

**Artículo traducido por Fabrizio López De Pomar para la revista Futuro Hoy del Fondo Editorial de la Sociedad Secular Humanista del Perú. Contacto: lopezdepomar.fabrizio@ssh.org.pe

\section{Cómo citar este artículo:}

Ord, T. (2021). Nueva ética para nuevos tiempos: la moral en la Industria 4.0 (F. López De Pomar, Trad.) Futuro Hoy, 2(1), 6-7. https://doi.org/10.52749/fh.v2i1.1. (Trabajo original publicado en 2020).

Esta obra está bajo licencia internacional

Creative Commons 4.0 Reconocimiento 4.0. 